\title{
Intelligent Interactive English Teaching Discrete Data Modeling and Simulation
}

\author{
Xin Li \\ Zhengzhou Railway Vocational and Technological College, Zhengzhou 450052, Henan, China \\ Correspondence should be addressed to Xin Li; 201309020138@stu.sdnu.edu.cn
}

Received 7 December 2021; Accepted 31 December 2021; Published 25 January 2022

Academic Editor: Sheng Bin

Copyright (c) 2022 Xin Li. This is an open access article distributed under the Creative Commons Attribution License, which permits unrestricted use, distribution, and reproduction in any medium, provided the original work is properly cited.

\begin{abstract}
This study attempts to explore the discrete data modeling and simulation of smart interactive English teaching based on mobile APP, expecting to explore the effective teaching strategies for deep integration of mobile APP technology and smart interactive English teaching, and to conduct discrete data modeling and simulation of English teaching. In this study, we propose a discrete data modeling algorithm for smart interactive English teaching based on discrete data points and normal vectors using B splines. By adding normal vector constraints, this method can maintain good fitting results even when the data points are discrete. The method consists of four parts, namely, discrete point parameterization, B-spline dominant point selection, node vector determination, and least-squares fitting, including both data point error and normal vector error. The mobile APP-based initial intelligent interactive English teaching should adhere to the four principles of autonomy of English course learning, adhere to teacher dominance in the language classroom, grasp the humanistic nature of English course content, and focus on the practical nature of English course implementation. The interactive learning environment based on mobile APP can promote students' in-depth understanding of knowledge. The higher the student's interest in learning, the deeper the degree of understanding; the more diverse the learning methods, the more it can promote students' in-depth understanding of knowledge; the stronger the degree of interaction, the higher the level of understanding. The discrete data modeling of smart interactive English teaching proposed in this study provides a theoretical reference for the design and production of interactive learning resources for English courses, according to which the interactive learning resources for English courses are produced to make up for the lack of English course resources.
\end{abstract}

\section{Introduction}

Mobile APP teaching is a teaching method that combines text, graphics, images, sound, animation, and video in one. Mobile APP teaching has rapidly developed and is welcomed by teachers and students because of the characteristics of personalized teaching methods, diversified learning methods, diversified information carriers, and an independent learning environment. Based on these advantages, interactive mobile APP technology is a rational learning tool, especially for language learners. An interactive mobile APP is based on traditional media with interactive features [1]. Traditional media bring audiences only visual and auditory senses, but interactive mobile APP audiences can also touch, feel, and even interact with it. An interactive mobile APP is a new form of media, which presents information with richer senses and brings people a new experience [2]. As more and more mobile APP technology tools are applied to the teaching process, more and more information-based devices appear. Interactive mobile APP teaching is conducive to the creation of students' thinking space, the substantial improvement of classroom efficiency, and the concretization of constructive cognition. The purpose of our study is to summarize and analyze from teaching practice, standardize mobile APP English teaching, analyze how to ensure the quality of English teaching, and effectively use interactive mobile APP tools to bring a new source of power to teach, to further deepen the pace of classroom reform [3].

At present, mobile APP is becoming more and more diversified and the market demand is increasing; as a new type of learning tool, if its product positioning and content form cannot adapt to the development of the current mobile APP learning environment and do not transform and upgrade in time according to the change of user demand, it will 
easily fall into a development dilemma and face the danger of being eliminated. How to make users more conveniently and efficiently participate in independent learning, truly understand user groups, meet user needs, create an independent learning environment, and meet English learners' expectations to assist their language learning are all issues that mobile APP developers should consider and solve, and new opportunities and challenges that need to be faced in the development of this field. This study discusses learners' usage preferences, attitudes, needs, opinions, and feedback in the context of the survey results on English learners' use of mobile APPs, analyzes the strengths and weaknesses of existing representative mobile APPs, and provides an indepth analysis of the product content, interface, functions, and promotion to provide new ideas and improved methods for the development of mobile APPs from a practical level. The method of constructing curves using the nature of flow lines has attracted the attention of scholars at home and abroad, and the problem of constructing curves using the flowline method and planning for tool paths of machining has been studied [4]. The interactive learning method based on mobile APP provides learners with learning scaffolding better and faster, assisting them to master the methods and thinking habits of autonomous learning faster, attracting their attention and increasing their interest in learning [5].

The mobile, convenience, visualization, gameplay, and personalization features of the mobile APP can stimulate secondary school students' interest in learning, put their spare time fragments to use, and provide students with supplementary learning [6]. At the same time, the mobile APP system has built-in videos of famous lecturers, periodicals, newspapers, and books for students to extensively dive into and expand their reading. It facilitates two-way interaction between teachers and students, creating a learning environment across time and space for students to realize interactive teaching [7]. Outside of the classroom, it cultivates learners' ability to apply theories acquired in the classroom to practice, allowing for independent inquiry learning, social learning, and the integration of theory and practice. This study is divided into six chapters. The first chapter is the introduction part, which mainly defines the scope, research background, and research methods and significance of this study on discrete data modeling and simulation of intelligent interactive English teaching based on mobile APP. The second chapter is the related work part, which mainly discusses the theoretical basis of discrete data modeling and simulation of intelligent interactive English teaching based on mobile APP, and additionally elaborates the current status of domestic and international research. Chapter 3 is mainly based on the research of smart interactive English teaching discrete data modeling by mobile APP, specifying the research object, selecting the research tools, meticulously designing the research process, and proposing a specific lesson plan design for English teaching discrete data modeling research. Chapter 4 is the result analysis section, which describes the experimental process in detail. After comparing the pre- and post-tests of the control class and the experimental class, the impact of intelligent interactive ELT discrete data modeling to assist English teaching is objectively analyzed from the data perspective. The simulation analysis is compared mainly from four aspects: listening and speaking scores, vocabulary scores, reading scores, and overall scores. In Chapter 5, the conclusion section, the author summarizes the teaching insights gained from this study, analyzes the shortcomings found in the study, and puts forward suggestions for future research.

\section{Related Work}

In terms of cognition and teaching, the most researched aspect of mobile APP learning is the possibility and feasibility of applying mobile devices to actual teaching and learning. Some researchers start from the basis of learning theory and verify through experiments that learners' learning effect is significantly improved with the assistance of new technology, which lays a solid foundation for further research and application of mobile APP learning [8]. Farouk A et al. conducted experiments on discrete data modeling and simulation of intelligent interactive English teaching, and the experiments focused on whether the service is effective when applied to educational teaching and learning [9]. Bryndin $E$ et al. conducted a study on smart interactive English teaching discrete data modeling and simulation, and the results indicated that discrete data modeling is perfectly feasible as a mobile APP learning aid for educational teaching. It not only helps learners regularly communicate but can also be useful for important information dissemination, classwork information, and scheduling [10]. Seddari $\mathrm{N}$ et al. point out that language is interactive, and through interaction, students can increase their language storage while listening to or reading authentic language materials and can even increase their classmates' output. In interaction, students can use all of the languages they already know or have unconsciously learned in real-life communication [11]. Research has shown the importance of interaction for teaching vocabulary and language and that mastery of vocabulary necessarily involves the impact of memory on learning [12]. The traditional teaching model is a receptive teaching mode. What is taught by teachers and what students are learning? The learning method of students is relatively simple. Intelligent interactive learning based on mobile APP can broaden learning channels and discover "potential courses" and "hidden courses." A "curriculum" is created in practice.

With the rise of the mobile internet, online education is also gradually enhanced to cell phone mobile, and many cell phone users look for the advantages of education class practicality, easy to carry, small, and beautiful interface [13]. Yang $L$ I et al. systematically introduced human memory laws, such as the functional principles of the left and right brain and the principle of the law of forgetting, gave corresponding suggestions based on these laws and principles, and put forward associative. These mnemonics can guide the strategic design of this study in vocabulary memory [14]. After being exposed to a large number of reports on human memory, $\mathrm{Xu} T$ et al. introduced some memory laws that are different from the popular perception and advocated the use of fractional time to learn and memorize English words [15]. 
Wang $M$ et al. conducted a study on teachers' teaching in the mobile APP environment through a quantitative analysis. The study found that teachers mainly used mobile APP technology for teaching content presentation; student-student and student-resource interactions only accounted for $32.89 \%$ [16]. The use of mobile APP technology can create a context for teachers' teaching and help teachers' activities with students to smoothly run. However, at this stage, the use of mobile APP technology in teaching still has problems such as not highlighting the subjectivity of students [17].

Existing interactive tools focus on real-time interaction but lack a targeted knowledge exchange sharing platform. It is more convenient for students to communicate in realtime. However, it is not convenient for students to share and evaluate works in real time. There is a lack of a curriculumrelated, systematic mobile learning interactive environment [18]. Mobile APP learning emphasizes the transfer of knowledge and gradually changes from a designated knowledge transfer model to an integrated inquiry-based learning model based on the mobile APP learning environment that emphasizes problem-centered learning. From the above literature, it can be seen that the study of English learning APPs has gradually received attention from the academic community and has been studied from different perspectives [19]. The overall research initially tended to analyze specific English learning APPs, and literature has emerged only in recent years that investigates from learners' perspectives and derives learners' usage experiences and feedback studies, but the number is still not significant. This is related to the specificity of language learning and the fact that the English learning APP market is still in the initial development stage and has not formed an independent and systematic classification of resources, which leads to some limitations in applied research. Throughout the language learning APPs in the market, English APP products have developed more mature and systematic in terms of content and technology, but with the trend of "English fever" in recent years, English teaching, acquisition, and English learning APPs are generally achieving quantitative to qualitative development [20].

\section{Research on Discrete Data Modeling of Intelligent Interactive English Teaching Based on Mobile APP}

\footnotetext{
3.1. English Teaching Mobile APP Intelligent Interactive Teaching Design. Interactive mobile APP technology creates powerful conditions for independent English learning. After learners obtain a large number of learning resources with the reference value, a variety of applications perfectly combine vocabulary, grammar, example sentences, and other materials with video, audio, and other mobile APP materials to create a rich, authentic audiovisual environment conducive to inspiration and attraction for learners. The interactive mobile APP environment can stimulate students' wholebody responses, and the computer can intelligently analyze students' behaviors, accurately evaluate the effectiveness of students' behaviors, and provide immediate feedback to
}

teachers and students, who can promptly correct their learning behaviors and reinforce the effectiveness of learning. This study also focuses on how the interactive mobile APP facility provides students with good conditions for independent learning.

The full use of interactive mobile APP makes mobile APP applied to educational information of images, sounds, diagrams, and texts, showing its advantages of intuitive images, so that students are not satisfied with the existing thinking program under the stimulation of rich external materials, generating interest in exploring learning and laying a good psychological foundation for English listening, reading, and vocabulary learning. At the same time, according to the requirements of the curriculum reform, the interactive mobile APP form of teaching can flip the classroom, so that the traditional teacher-centered classroom is completely overturned. The modern English classroom is student centered, task based, and activity mediated. The teacher guides students to understand the background content of the listening materials, stimulates students' interest in exploring background knowledge, uses the mobile APP teaching environment, introduces cleverness, deepens new knowledge, consolidates old knowledge, and provides students with specific tasks to let them know what they will do.

By designing the basic process of an interactive English classroom, taking the integrated reading class type as an example, and simultaneously training students' listening, reading, and writing skills, observing the convenience and shortcomings of teachers and students in using interactive devices, analyzing the experimental results, i.e., integrating students' output scores and interviewing students' actual English learning to confirm the superior ability of interactive media, and exploring how to more effectively use interactive mobile APP devices, the results of the experiment were analyzed to confirm the superiority of interactive media and to explore how to more effectively use interactive mobile APP devices. This lesson plan was tried on mobile APP devices above the interactive whiteboard, the classroom will also become mainstream in the future, and the classroom is more suitable for this interactive mobile APP teaching study. This study tries to design a mobile APP mobile learning software to assist the teaching of this course to improve the learning and teaching effect, as shown in Table 1 . In the course content arrangement, mastering composition methods, color usage, light techniques, and processing methods in photography technology is the main learning objective of this course. The current mobile APP not only has the function of shooting and storing but also has the function of information interaction and resource sharing that traditional cameras do not have. You can first let students practice shooting with their cell phones, with a certain foundation, and then shoot with a camera, so you can achieve twice the result with half the effort. In addition, the development of a mobile APP-based interactive platform for the exchange of ideas between students, sharing resources, and displaying works to build a mobile learning environment can promote the effective improvement of learning and teaching quality. 
TABLE 1: Comparison table of interactive course features.

\begin{tabular}{lcc}
\hline Category & Intelligent interactive course & General course \\
\hline Course characteristics & Autonomous teaching model & Teacher centered \\
Time and place & Voluntary & Fixedness \\
Course content & Nonmandatory & Mandatory \\
Resource type & Interactive language and audio & Textbooks and videos \\
Learning purpose & Expand teaching content & Complete the teaching task \\
Platform interface & Clear and easy to understand & Powerful and less used \\
\hline
\end{tabular}

The mobile APP instructional design architecture consists of five main parts, as shown in Figure 1, including the application layer, the application framework layer, the runtime and system library layer, and the Linux kernel layer. The bottom layer of the system architecture provides services for the upper layer. The data are imported into the modeling system software for model construction. Profile data, borehole data, surface discrete point data, and English teaching data are imported into the work area, and each model element in the sequence is built according to a certain modeling sequence.

The interactive function of mobile APP is incomparable to other communication media, it overcomes the limitation of one-way communication mode, mobile APP realizes the interaction of users all the time, users are not restricted by time and place, they can send and receive information on demand, make contact and interaction between individuals or groups, increase the opportunity of communication between teachers and students, as long as students have questions, they can raise them in time, and teachers can make answers in time. As long as students have questions, they can ask and teachers can answer them in time. One of the main features of mobile learning is that the information is quickly updated, and the difference with the previous online English teaching is that learners can access the latest learning content at the first time, and as long as the premise of meeting the network, mobile applications can be pushed at all times, truly ubiquitous learning, and improve learning interest.

3.2. Discrete Data Modeling Design for English Language Teaching. Based on the theoretical basis of the interactive learning environment based on mobile APP, the interactive learning environment is characterized by mobile learning tools, interactive learning methods, free presentation conditions, fragmented learning contents, graphic presentation of resources, and real-time information pushing. The author proposes six interactive learning environment strategies based on these six interactive learning environment characteristics, which are shown in Table 2.

In ELT data fitting, the selection of parameter values $f(k)$ and node vectors $Q$ is crucial to the quality of the fitted data. Uniform parameterization means that the parameter points are uniformly distributed in the parameter space. For a known discrete point $\left\{L_{k}, k \subseteq[1, n]\right\}$, its corresponding uniform parameterization $F=\{f(k)\}$ is shown in the following equation:

$$
f(k)=\frac{k-1}{n-1}, k \subseteq[1, n] .
$$

When the data points are not uniformly distributed, the cumulative chord length parameterization method can be adopted, and the chord length between two adjacent discrete points $L_{k-1}$ and $L_{k+1}$ is noted as $\left|L_{i} \underset{L_{k+1}}{\rightleftarrows}\right|$ and then as the corresponding parameterization formula in equation (2). The effect of adjusting the size of a vector on the curve cannot be directly seen. Since the power base does not satisfy the unit decomposition, after the curve generated by it undergoes linear change or translation, its geometric shape will change, which makes it difficult for us to operate and modify on its basis.

$$
\left\{\begin{array}{l}
f(0)=0 \underset{L_{i} L_{k-1} \mid}{\rightleftarrows} f(n)=1 \\
f(k)=\sum_{i=1}^{n}\left|L_{i} L_{k+1}^{\rightleftarrows}\right|
\end{array}\right.
$$

Among the methods without reference to discrete point parameters, quasi-uniform nodes are one of the most widely used methods. The corresponding formula is shown in equation (3). For the method concerning the discrete point parameter values, the node vector $u$ i is usually determined by $\mathrm{F}$, the number of required control nodes is $n+1$, and the number of known discrete points is $k+1$.

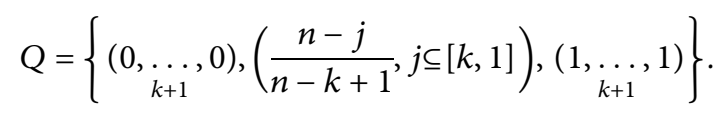

The node vector is determined to reflect the distribution of discrete point parameter values and to ensure that each node span contains at least one parameter value. To preserve the endpoint property, the B-spline curve is generally made to interpolate at both control vertices, which implies that the number of node weights at both ends of the node vector is $k+1$. In addition, the internal nodes of the node vector can be shown by

$$
Q(k+i-1)=\left\{\frac{\sum_{i=1}^{i+k-2} q(i)}{h-1}, h=n(1-w)^{*} q(h-1)+w^{*} q(h), h>n, i \subseteq[1, n-k+1],\right.
$$




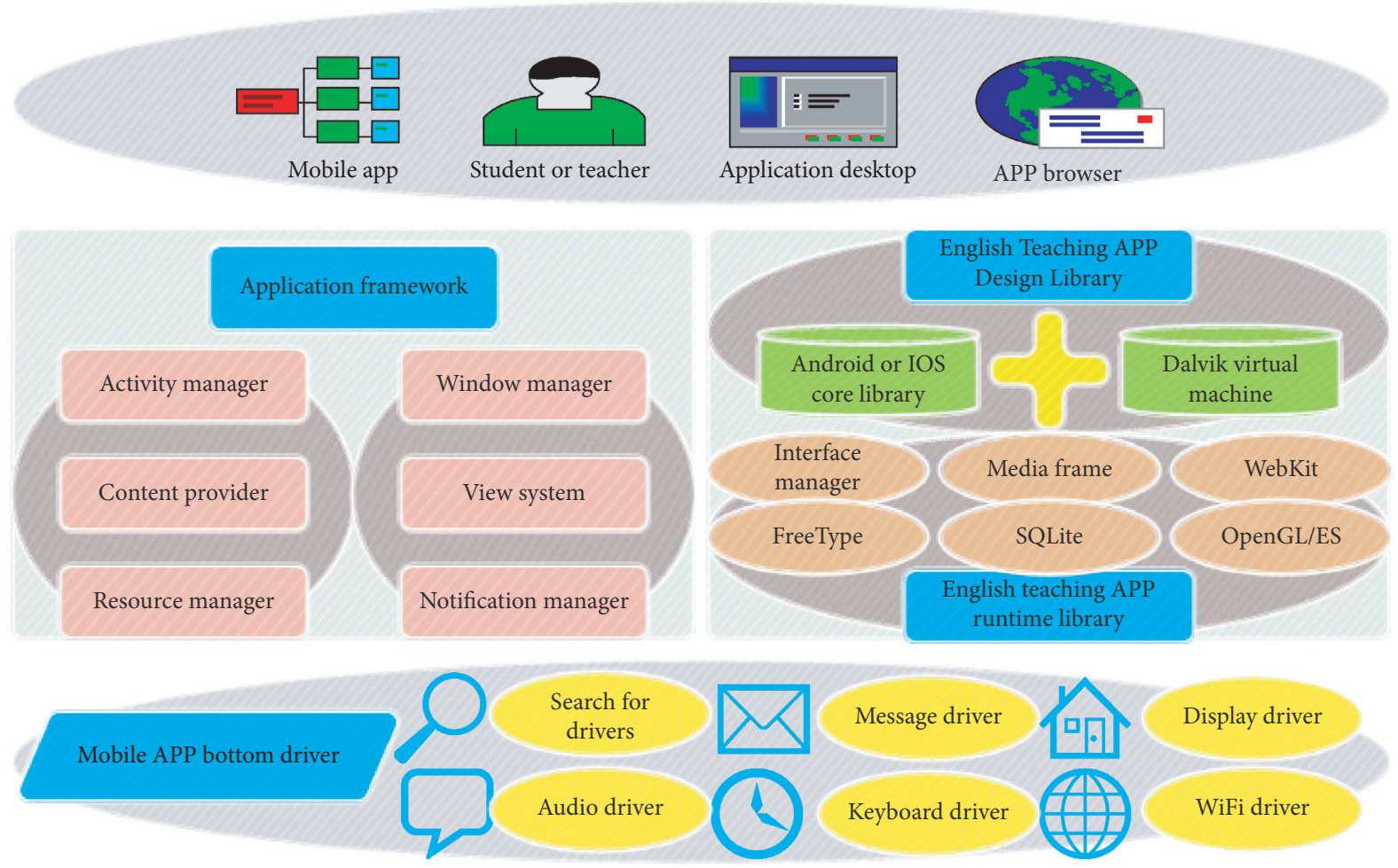

FIgURE 1: Mobile APP teaching design architecture.

TABLE 2: Learning environment construction strategies.

\begin{tabular}{|c|c|c|c|c|}
\hline $\begin{array}{l}\text { Strategy build } \\
\text { number }\end{array}$ & $\begin{array}{c}\text { Interactive teaching } \\
\text { information }\end{array}$ & $\begin{array}{l}\text { English teaching } \\
\text { characteristics }\end{array}$ & $\begin{array}{l}\text { Main strategies of teaching } \\
\text { construction }\end{array}$ & $\begin{array}{l}\text { Secondary strategies of } \\
\text { teaching construction }\end{array}$ \\
\hline 1 & Learning tools & Mobile & Smartphones as a learning tool & $\begin{array}{c}\text { Android and IOS operating } \\
\text { systems }\end{array}$ \\
\hline 2 & Learning method & Interactive & $\begin{array}{l}\text { Teacher-student interaction and } \\
\text { student-student interaction }\end{array}$ & Student-resource interaction \\
\hline 3 & Presentation condition & Liberalization & Use arbitrariness & Freedom of sharing \\
\hline 4 & Learning content & Fragmentation & English knowledge time control & English video time control \\
\hline 5 & Resource presentation & Pictorial & Use of knowledge points display & $\begin{array}{l}\text { The utilization rate of } \\
\text { teaching activity design }\end{array}$ \\
\hline 6 & Information push & Real time & Quick update of learning content & $\begin{array}{l}\text { Offline update of learning } \\
\text { content }\end{array}$ \\
\hline
\end{tabular}

where the value of $k$ is shown by equation (5). This method uses the average (AVG) technique when $k=n$ and the node placement (KTP) method when $k>n$. This method is very sensitive to discrete points carrying dispersion when $k$ and $n$ are close, and some scholars combine the energy term with least squares to improve the stability of the reconstruction curve by fitting the algorithm.

$$
\left\{\begin{array}{l}
h=\left[k^{*} q\right]^{*} w \\
q=\frac{k+1}{n-k+2} \\
w=k * d-n
\end{array}\right.
$$

When the set of known discrete points contains low dispersion strength, the curvature values on the data points are calculated using the local method. When the dispersion intensity is high, the curvature values obtained using the local method also contain strong dispersion. In this case, cubic B-sample curves $M^{\prime}(q)$ and $M^{\prime \prime}(q)$ are fitted using the holistic method. Based on the base curve, the curvature value $Z(i)$ corresponding to the data points is obtained using the following equation:

$$
Z(i)=\frac{M^{\prime}(q(i))^{*} M^{\prime \prime}(q(i))}{M^{\prime}(q(i)} .
$$

Using the obtained dominant points $h_{j}$, the original data point set is divided into multiple segments according to the order of the dominant points. Taking $M_{m, e}$ as an example, we 
introduce how to select new dominant points in $M_{m, e}$, where $h_{j}=L_{m}$, and $h_{j+1}=-L_{e}$. All line segments containing three or more points are selected $(e-m>1)$, and among these line segments, the point $L_{c}$ with the largest deviation from the fitted curve $M(q)$ is found, and its deviation is shown in the following equation:

$$
\| M_{m, e}\left(q(i)-L_{i} \| .\right.
$$

The approximation error of the fitted data to the noisy data is shown by equation (8). The $\beta$ is called the regularization parameter.

$$
W(x)=\beta^{*} \int M^{(k)}(x)^{2} \mathrm{~d} x .
$$

In language learning, classroom learning and learning in the target language are the most important language learning channels, but mobile learning, represented by APPs, provides a new option for learners who do not have either of these conditions. Language learners who are unable to participate in classroom learning due to constraints can also access a vast amount of learning resources through the APP learning platform. Learning a language requires a great deal of exposure to the target language and culture, and for learners who do not have access to the target language environment, learning a language through the use of an APP is not only free of time constraints but also breaks the limits of physical space, allowing learners to receive a certain level of input from the target language in a nontarget language environment. For the relatively small learning units that appear in language learning, learners can learn and practice anytime and anywhere.

\section{Analysis of Results}

4.1. Intelligent Interactive Analysis. This study investigated the teaching efficiency of interactive mobile APP-assisted English language teaching in vocabulary. The results of the study showed that interactive mobile APP-assisted English language teaching is an effective tool for English vocabulary structure mastery. Individuals learned and remembered more words in the interactive mobile APP environment. Figure 2(a) shows the data test of the pre-experimental class and the control class with percentages of scores. The content of the test was English vocabulary knowledge, which was standardized according to the requirements of the secondary school examination. The test took one hour and was independently completed by the students. Figure 2(b) shows the scores of the experimental class compared with the control class after using the interactive mobile APP for teaching two tests.

A total of 300 questionnaires were distributed, including 100 pre-tests and 1000 post-tests for the control group and 200 post-tests for the experimental group, and 100 pre-tests and 100 post-tests for the experimental group, with a total of 200 questionnaires distributed. The pre-test questionnaire was distributed at the same time as the pre-test in the quasi-laboratory teaching evaluation session, and the post-test questionnaire was distributed at the same time as the follow-up test in the third round of quasi-laboratory teaching evaluation sessions. The questionnaire options were based on Likert's option classification of the questionnaire: strongly disagree was 1.6 , relatively disagree was 2 , indifferent was 3 , relatively agree was 4.2 , and strongly agree was 5.1 representing the highest interest. After excluding the invalid data (invalid data included the data of questionnaires in which all options filled by students were one item and the data of questionnaires that were missed or not filled according to the requirements of the questionnaire), the data before and after the test in the two classes were organized as shown in Figure 3.

As shown in Figure 4, 38.93\% of the students occasionally use the APP every week, which means that they do not use the APP every day. Some possible reasons are analyzed: the course is a weekly class, and most of the students choose to open the APP three or five days before the course starts to check the homework and requirements and upload photographs to complete the homework, which means that the students are interested in using the APP, but they still stay at the level of completing homework. This indicates that students are interested in using the software, but they are still at the level of completing assignments.

The study concluded that the degree of interaction and insight and empathy correlated the most, meaning that the stronger the degree of interaction of students, the better they learn to gain insight into others' works and perspectives, the better they are at transferring their knowledge, and the more they improve their ability to gain insight and transfer in the process of communication and exchange. The degree of interaction had the weakest correlation with interpretation and interpretation in the comprehension hierarchy, indicating that the degree of interaction did not significantly correlate enough with the ability to interpret and explain for this more operational course.

\subsection{English Teaching Discrete Data Simulation Analysis.} Ten IT teachers of English courses were selected for the ELT discrete data simulation, and the teachers were shown a video introducing the interactive learning resources of the intelligent design course and the classroom recording of students using the interactive learning resources, and then, a questionnaire was administered to the teachers. In the process of filling out the questionnaire, some specialized terms were explained to ensure the validity of the questionnaire. Ten valid questionnaires were collected, their results were analyzed, and the experimental results are shown in Figure 5. From the overall results of the questionnaire, no teachers chose the options of "strongly disagree" and "disagree," and the overall choice was mainly "agree," indicating that teachers feel good about the use of interactive learning resources. The use of interactive learning resources allows students to control their learning progress, self-evaluate their learning status through testing questions, promote the independent construction of learners' knowledge, and realize deep-level active interaction between learners and learning resources.

We compare the results obtained by the three methods for intelligent interactive English teaching at different 


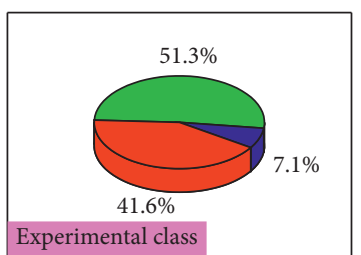

$\square \leq 60$
$\square$
$60-90$
$\geq 90$

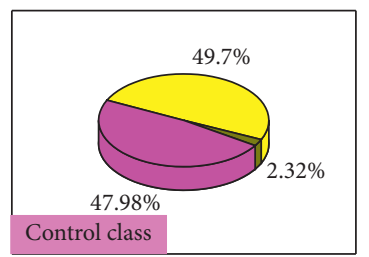

$\leq 60$

$\square 60-90$

$\square \geq 90$

(a)

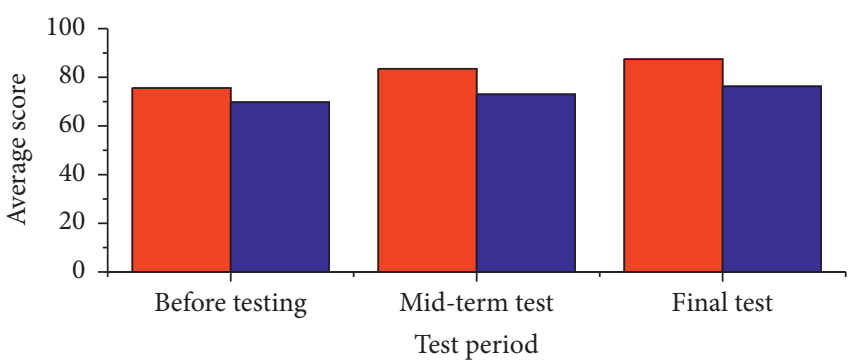

Experimental class

Control class

(b)

Figure 2: Comparison results of experimental vocabulary scores between the experimental and control classes. (a) Comparison table of vocabulary score test before. (b) Before and after the average score of the vocabulary test score comparison table.

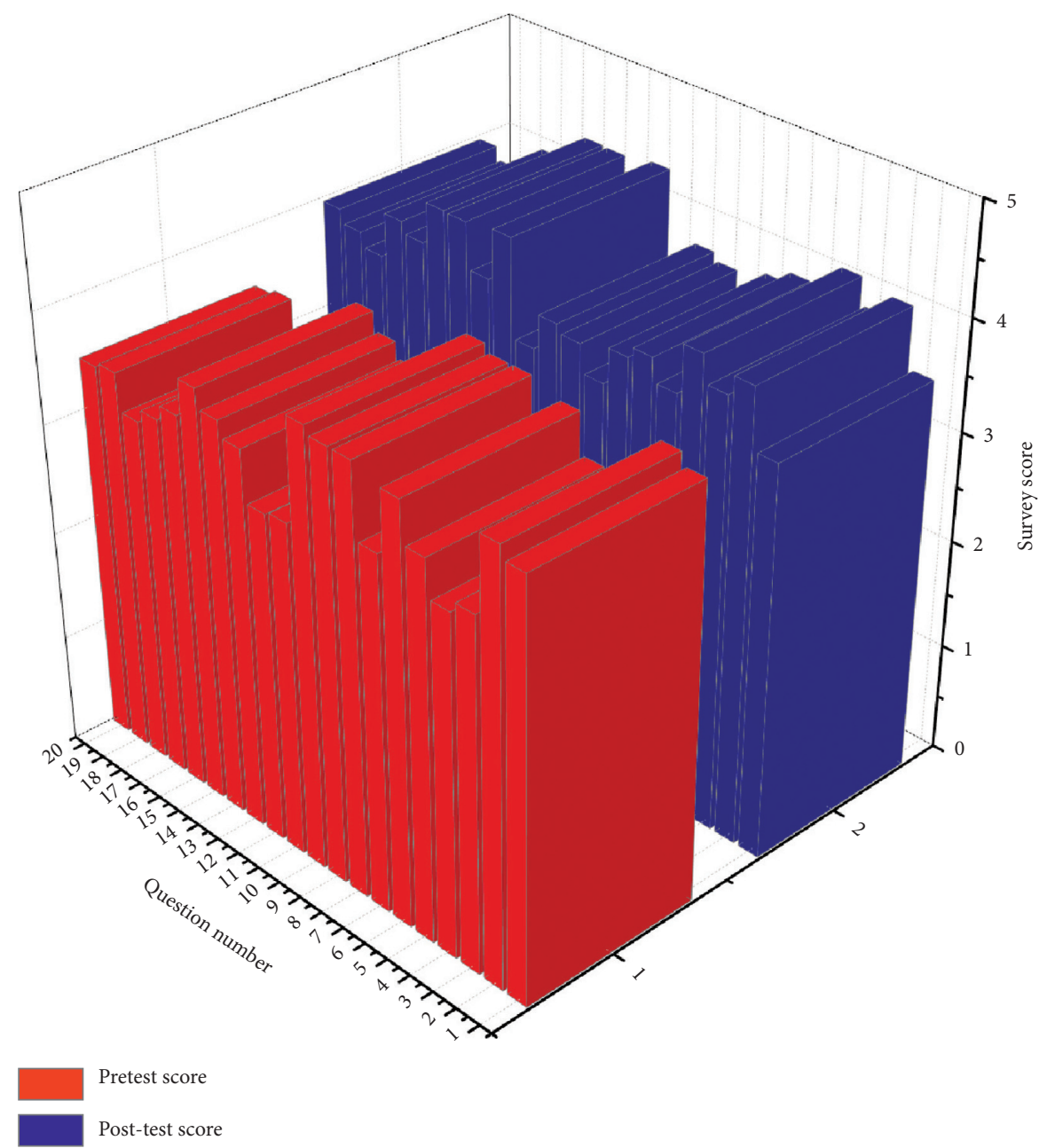

FIgURE 3: Comparison of questionnaire subscores in the control group.

discrete strengths. We compare the three methods in terms of the deviation size of the reconstructed data and the running time of the methods themselves. For the DOM method and this study, we also compare the number of selected dominant points. The deviation sizes of the reconstructed data for the three methods are shown in Figure 6, which shows the errors in the location coordinates between the reconstructed data and the original data based on the ELT data points for the regularization method, the DOM method, and this method.

Figure 7 shows the number of dominant points required for the DOM method and this method to reconstruct the ELT data. In Figure 7(a), we can see that when the discrete data are small, the number of dominant points required by 

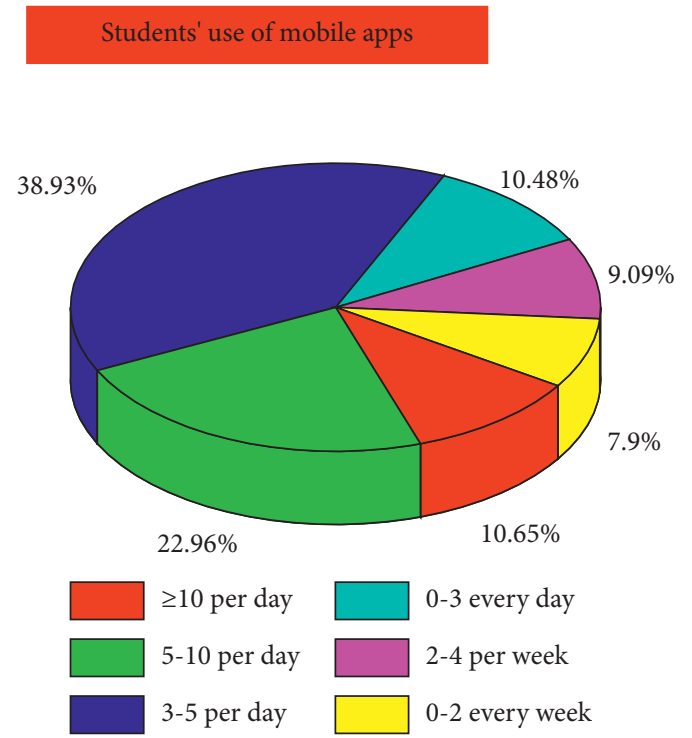

Figure 4: Frequency analysis of students' usage.

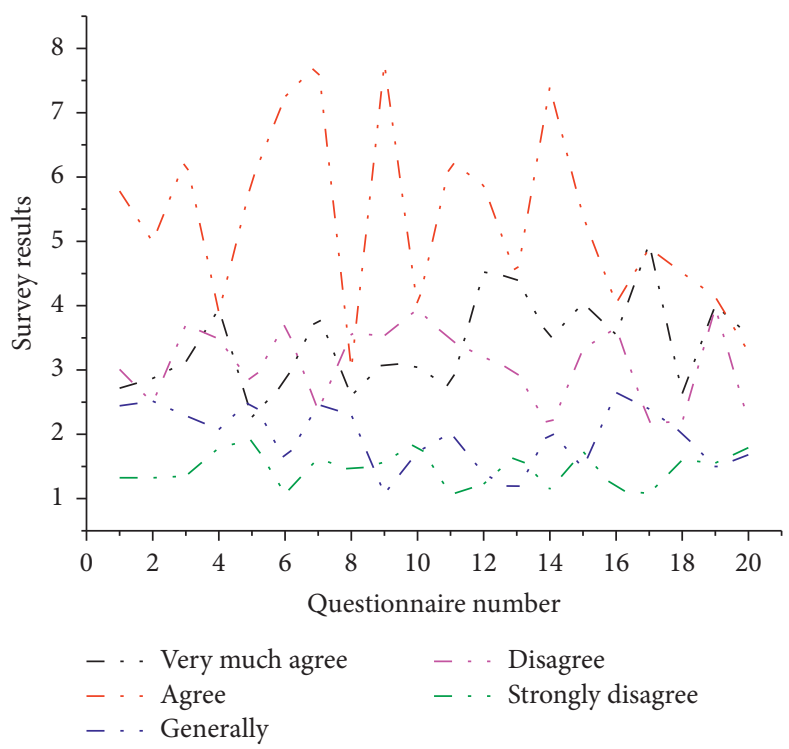

FIGURE 5: Statistics of teacher evaluation results.

this method is small; while the discrete data are large, the number of dominant points required by the DOM method is small, because the DOM method only uses the least-squares method as the curve fitting algorithm, and the selection of more dominant points when the discrete is large will lead to unstable results and cannot get effective results so that the number of dominant points cannot be increased. The number of points cannot be increased. In Figure 7(b), we can see that the method in this study only needs to select fewer dominant points to obtain a better reconstruction curve. In addition, when the data are discrete, the DOM method needs to artificially give parameters and control the number of vertices to obtain the base curve, which also makes the practical application more difficult.

As shown in Table 3, among all the reasons for use, the easy way of learning and the ease of increasing interest motivation became the most important reasons for most learners to choose English learning APPs. Learners' intention and motivation to actively learn are important factors affecting language learning, and this depends on whether learners can generate a sense of pleasure and accomplishment in the learning process. The APP improves the fun of learning materials and ways in its unique way, expands the presentation dimension of traditional textbooks such as language textbooks, and presents a variety of ways, which to a certain extent can improve learners' interest in English learning and thus achieve efficiency. The APP is a unique way to expand the dimension of traditional textbooks such as language materials and present them in a variety of ways.

Building virtual learning communities, strengthening the deep interaction of learners' online learning communication, and carrying out learning activities, cooperation, and 


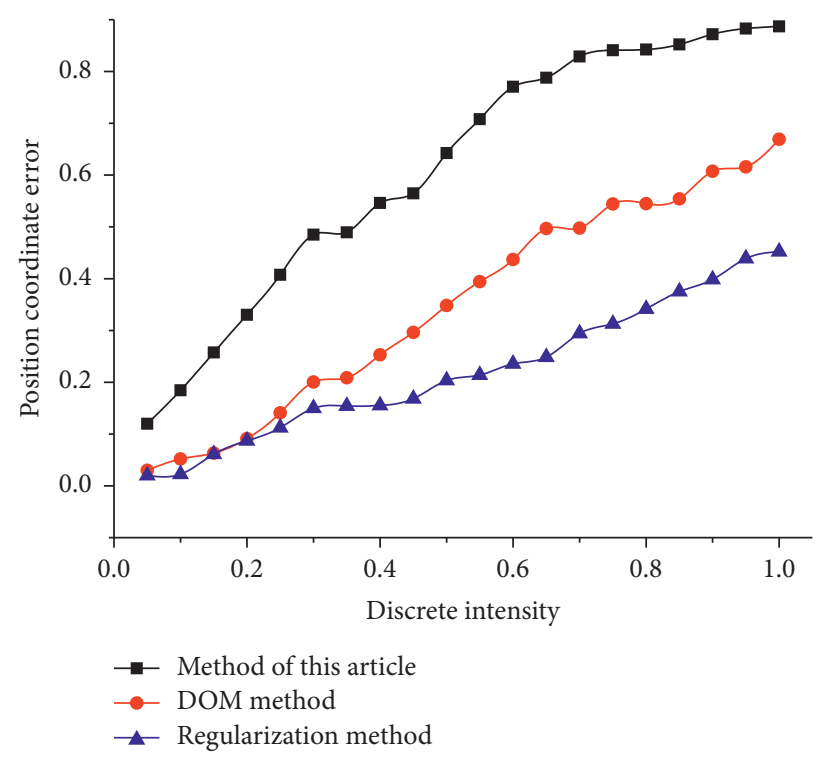

FIGURE 6: Maximum discrete point results.

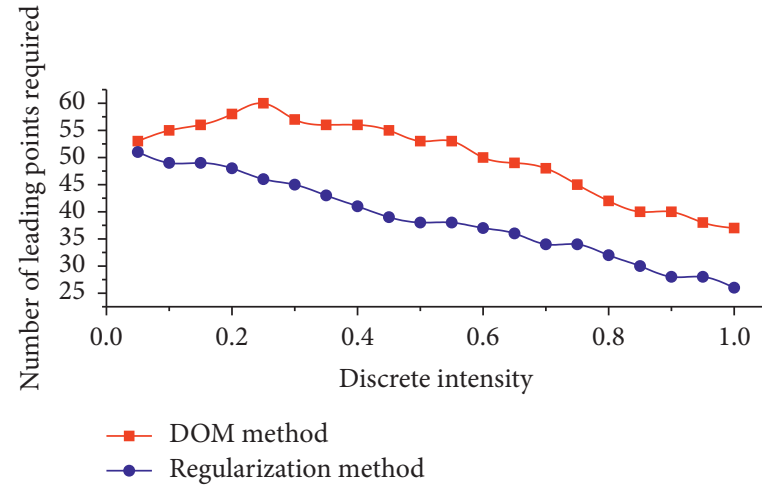

(a)

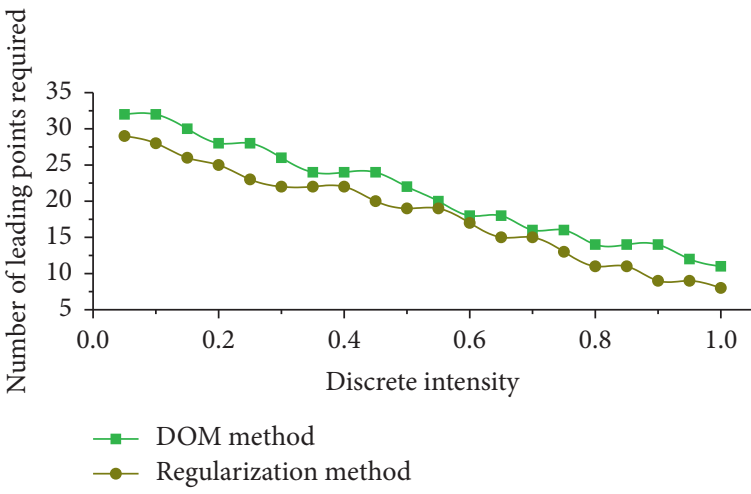

(b)

Figure 7: The number of dominant points required to reconstruct discrete data.(a) The number of leading points required for English teaching data set 1. (b) The number of leading points required for English teaching data set 2.

TABLe 3: Reasons for user's use.

\begin{tabular}{|c|c|c|c|c|c|c|c|c|}
\hline Options & A & $\mathrm{B}$ & $\mathrm{C}$ & $\mathrm{D}$ & $\mathrm{E}$ & $\mathrm{F}$ & G & $\mathrm{H}$ \\
\hline Number of choices & 67 & 27 & 59 & 19 & 19 & 8 & 10 & 17 \\
\hline The proportion of options (\%) & 29.65 & 11.95 & 26.11 & 8.41 & 8.41 & 3.54 & 4.42 & 7.52 \\
\hline
\end{tabular}

A: Easy learning, B: online interaction, C: easy and convenient, D: rich resources, E: targeted learning, F: simulate real-scene environment, G: popular recommendation, and $\mathrm{H}$ : rapid improvement.

communication through the community model built by the learning platform not only create a sense of belonging for learners and increase the pleasure of use but also help learners to reconstruct and understand knowledge through communication and sharing between learning with the help of their learned knowledge in the interaction process. Teachers need to continuously enrich their knowledge, study textbooks, study curriculum standards and other related knowledge, improve their professional quality, go deep into the students, analyze the students' situation in a timely and comprehensive manner, estimate the difficulties in the students' learning, formulate clear and appropriate teaching goals, design a reasonable teaching process, and make full use of modern teaching techniques to create a meaningful classroom.

\section{Conclusions}

After using the mobile APP interactive learning software, students can easily understand the knowledge, comprehend the knowledge, and master the knowledge, which is the level of explanation and interpretation in comprehensive learning; next, students start to skillfully use the mobile APP interactive 
learning software, continuously practice applying the knowledge contained in a class, and exchange and inspect the works of other students to reach the level of application and insight understanding in comprehension learning. In the end, students realize the transfer of knowledge and innovation under the teacher's comments and inspiration, identify the strengths and weaknesses of other students' works and discard them, and form their style of works in the process of continuous learning and self-improvement. The author believes that at this point the learner has reached the highest level of understanding, i.e., selfawareness. In terms of discrete point parameterization, an improved discrete point parameterization method is obtained by using known normal vector information, and the accuracy is greatly improved compared with previous methods. In the node vector determination, the dominant point selection method and the algorithm stopping condition are modified with the help of normal vector information, which makes the method require fewer dominant points, and more accurate dominant point selection, and the required computation time is greatly reduced. In terms of curve fitting, this method combines the normal vector fitting error to improve the curve fitting approximation model. Compared with previous regularization methods, the results obtained in this study can better maintain the overall shape of the curve. How effectively mobile APP technology can assist teaching and learning instead of putting the cart before the horse depends mainly on the users. Students are interested in the fun and interactive technology, but it is the knowledge itself that is often overlooked. In particular, students with low willpower do not get the maximum learning benefit. Therefore, it is important for teachers to emphasize their leading position in teaching and learning and to discipline and supervise students to learn on their own.

\section{Data Availability}

The data used to support the findings of this study are available from the corresponding author upon request.

\section{Conflicts of Interest}

The authors declare that they have no known competing financial interests or personal relationships that could have appeared to influence the work reported in this paper.

\section{References}

[1] X. Zhang and B. Alijla, "Research on inheritance and innovation mode of erhu art development based on intelligent algorithm," Journal of Intelligent and Fuzzy Systems, vol. 37, no. 3, pp. 3327-3334, 2019.

[2] K. Rakić, M. Rosić, and I. Boljat, "A survey of agent-based modelling and simulation tools for educational purpose[J]," Tehnički Vjesnik, vol. 27, no. 3, pp. 1014-1020, 2020.

[3] X. Ji, "Community guidance model based on interactive multimedia system," Multimedia Tools and Applications, vol. 78, no. 4, pp. 4723-4741, 2019.

[4] M. Schluse, M. Priggemeyer, L. Atorf, and J. Rossmann, "Experimentable digital twins-streamlining simulation-based systems engineering for industry 4.0," IEEE Transactions on Industrial Informatics, vol. 14, no. 4, pp. 1722-1731, 2018.
[5] B. Gan, C. Zhang, Y. Chen, and Y.-C. Chen, "Research on role modeling and behavior control of virtual reality animation interactive system in Internet of Things," Journal of Real-Time Image Processing, vol. 18, no. 4, pp. 1069-1083, 2021.

[6] E. Bryndin, "Increase of safety use robots in industry 4.0 by developing sensitivity and professional behavioral skills," American Journal of Mechanical and Industrial Engineering, vol. 5, no. 1, pp. 6-14, 2020.

[7] İ Gelir, "The investigation of Co-teaching model in second language teaching in early years education[J]," ELT Research Journal, vol. 9, no. 2, pp. 135-145, 2020.

[8] R. Hou, Y. Kong, B. Cai, and H. Liu, "Unstructured big data analysis algorithm and simulation of Internet of Things based on machine learning," Neural Computing \& Applications, vol. 32, no. 10, pp. 5399-5407, 2020.

[9] A. Farouk and D. Zhen, "Big data analysis techniques for intelligent systems," Journal of Intelligent and Fuzzy Systems, vol. 37, no. 3, pp. 3067-3071, 2019.

[10] E. Bryndin, "Development of artificial intelligence for industrial and social r," International Journal of Intelligent Information Systems, vol. 10, no. 4, pp. 50-59, 2021.

[11] N. Seddari, S. Boukelkoul, A. Bouras, M. Belaoued, and M. Redjimi, "A new transformation approach for complex systems modelling and simulation: application to industrial control system," International Journal of Simulation and Process Modelling, vol. 16, no. 1, pp. 34-48, 2021.

[12] D. A. Hashimoto, E. Witkowski, L. Gao, O. Meireles, and G. Rosman, "Artificial intelligence in a," Anesthesiology, vol. 132, no. 2, pp. 379-394, 2020.

[13] S. Khan, A. Al-Dmour, V. Bali, M. R. Rabbani, and K. Thirunavukkarasu, "Cloud computing based futuristic educational model for virtual learning," Journal of Statistics \& Management Systems, vol. 24, no. 2, pp. 357-385, 2021.

[14] L. I. Yang, J. Huang, T. Feng, W. A. N. G. Hong-An, and D. A. I. Guo-Zhong, "Gesture interaction in virtual reality[J]," Virtual Reality \& Intelligent Hardware, vol. 1, no. 1, pp. 84112, 2019.

[15] T. Xu, G. Song, Y. Yang, P.-x. Ge, and L.-x. Tang, "Visualization and simulation of steel metallurgy processes," International Journal of Minerals, Metallurgy and Materials, vol. 28, no. 8, pp. 1387-1396, 2021.

[16] M. Wang and Y. Wang, "Research on English teaching information pushing method based on intelligent adaptive learning platform," International Journal of Continuing Engineering Education and Life Long Learning, vol. 31, no. 2, pp. 133-151, 2021.

[17] A. Kopper, R. Karkare, R. C. Paffenroth, and D. Apelian, "Model selection and evaluation for machine learning: deep learning in materials processing," Integrating Materials and Manufacturing Innovation, vol. 9, no. 3, pp. 287-300, 2020.

[18] X. Wang, Y. Han, V. C. M. Leung, D. Niyato, X. Yan, and $\mathrm{X}$. Chen, "Convergence of edge computing and deep learning: a comprehensive survey," IEEE Communications Surveys \& Tutorials, vol. 22, no. 2, pp. 869-904, 2020.

[19] S. C. Brailsford, T. Eldabi, M. Kunc, N. Mustafee, and A. F. Osorio, "Hybrid simulation modelling in operational research: a state-of-the-art review," European Journal of Operational Research, vol. 278, no. 3, pp. 721-737, 2019.

[20] M. Khatari, A. A. Zaidan, B. B. Zaidan, O. S. Albahri, and M. A. Alsalem, "Multi-criteria evaluation and benchmarking for active queue management methods: open issues, challenges and recommended pathway solutions," International Journal of Information Technology and Decision Making, vol. 18, no. 04, pp. 1187-1242, 2019. 